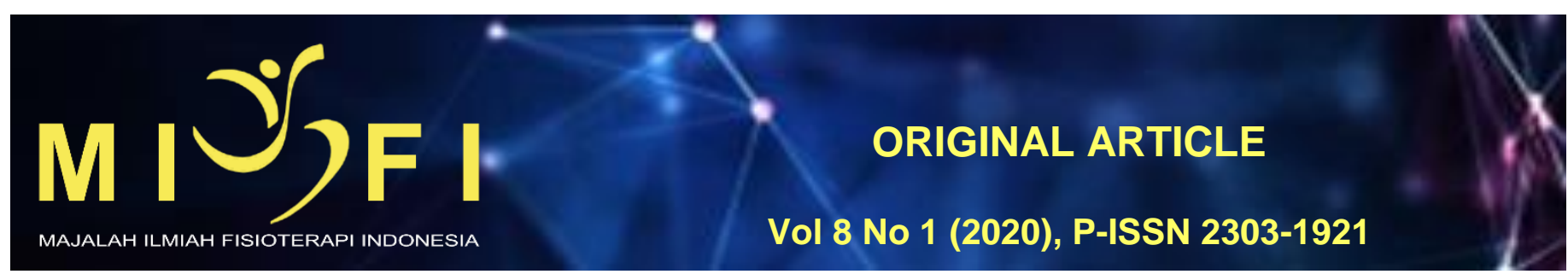

\title{
HUBUNGAN ANTARA POSTUR KERJA DAN MASA KERJA DENGAN TERJADINYA MYOFASCIAL PAIN SYNDROME OTOT UPPER TRAPEZIUS PADA PENJAHIT GARMEN DI BATUBULAN GIANYAR
}

\author{
Ni Kadek Mira Wirayani ${ }^{1}$, M. Widnyana ${ }^{2}$, Nila Wahyuni ${ }^{3}$, I Wayan Sugiritama ${ }^{4}$ \\ ${ }^{1}$ Program Studi Fisioterapi dan Profesi Fisioterapi Fakultas Kedokteran Universitas Udayana, Denpasar \\ ${ }^{2}$ Departemen Fisioterapi Fakultas Kedokteran Universitas Udayana, Denpasar \\ ${ }^{3}$ Departemen IImu Faal Fakultas Kedokteran Universitas Udayana, Denpasar \\ ${ }^{4}$ Departemen Histologi Fakultas Kedokteran Universitas Udayana, Denpasar \\ myrawirayani@yahoo.co.id
}

\begin{abstract}
ABSTRAK
Pekerjaan menjahit berisiko menimbulkan masalah ergonomik. Risiko tersebut timbul karena perilaku saat bekerja seperti posisi duduk yang lama dan melakukan gerakan berulang sehingga berisiko mengalami penyakit salah satunya musculoskeletal disorder. Tujuan penelitian ini untuk mengetahui hubungan postur kerja dan masa kerja pada penjahit dengan terjadinya myofascial pain syndrome. Penelitian ini menggunakan sampel sebanyak 91 orang. Pengumpulan data menggunakan metode observasi. Teknik sampel yang digunakan adalah purposive sampling. Teknik analisa data menggunakan Spearman's Rho test. Hasil penelitian menunjukkan ada hubungan yang signifikan masa kerja dengan MPS dengan korelasi sebesar 0,417 dan nilai $p$ sebesar $0,000(p<0,05)$ dan terdapat hubungan yang signifikan postur kerja dengan MPS dengan korelasi sebesar 0,481 dan nilai $p$ sebesar $0,000(p<0,05)$.

Kata kunci: penjahit, masa kerja, postur kerja, RULA, myofascial pain syndrome.

\section{RELATIONSHIP BETWEEN WORK POSTURE AND WORKING PERIOD WITH THE OCCURRENCE OF MYOFASCIAL PAIN SYNDROME UPPER TRAPEZIUS MUSCLES ON GARMENT TAILORS IN BATUBULAN GIANYAR}

ABSTRACT

Sewing jobs risk is causing ergonomics problems. These risks arise due to behaviour when working like a long sitting position and repetitive movements so that the risk of experiencing the disease is musculoskeletal disorder. The purpose of this research is to know the relationship of work posture and working period to the tailor with the occurrence of myofascial pain syndrome. The study used samples of 91 people. Data collection using observation methods. The sample technique used is simple random sampling. Data analysis techniques using the Spearman's Rho test. The results showed that there was a significant relationship between working period and the MPS with a correlation of 0.417 $(p<0.05)$ and there was an relationship between working posture measured with RULA and the MPS with a correlation of $0.481(p<0.05)$.
\end{abstract}

Keyword: tailor, work posture, working period, RULA, myofascial pain syndrome. 


\section{PENDAHULUAN}

Menurut UU No. 13 tahun 2003 Bab I pasal 1 ayat 2 disebutkan bahwa tenaga kerja adalah setiap orang yang melakukan pekerjaan guna untuk menghasilkan barang atau jasa yang baik untuk memenuhi kebutuhan diri sendiri maupun untuk masyarakat. International Labour Organization (ILO) memperkirakan setiap tahunnya sekitar 2,3 juta pekerja meninggal karena kecelakaan kerja dan penyakit akibat kerja. Hasil Studi Departemen Kesehatan dalam profil masalah kesehatan di Indonesia tahun 2005 menunjukkan bahwa sekitar 40.5\% penyakit yang diderita pekerja berhubungan dengan pekerjaannya. Salah satu pekerjaan yang memiliki risiko mengalami penyakit akibat kerja adalah penjahit.

Penjahit merupakan salah satu jenis pekerjaan yang ditekuni oleh sebagian masyarakat Indoneisa. Pekerjaan menjahit biasanya didominasi oleh wanita. Occupational Safety and Health Administration (OSHA) menyebutkan bahwa pekerjaan menjahit berisiko menimbulkan masalah ergonomik. Risiko tersebut timbul karena perilaku saat bekerja seperti posisi duduk yang lama dan melakukan gerakan berulang sehingga berisiko mengalami penyakit salah satunya musculoskeletal disorder (MSDs).

Musculoskeletal Disorders (MSDs) merupakan penyakit akibat kerja yang paling banyak terjadi pada proses penjahitan pakaian. Besarnya kasus dan dampak yang ditimbulkan oleh gangguan kesehatan pekerja. Berdasarkan penelitian Aryanto ditemukan bahwa dalam posisi menjahit, 82,5\% mengalami keluhan pada pinggang, 60\% pada bokong, $57,5 \%$ pada leher bagian bawah, $47,5 \%$ pada leher bagian atas, dan $45 \%$ pada bahu. ${ }^{1}$ Berdasarkan penelitian yang dilakukan oleh Sihombing tahun 2015 pada penjahit, ditemukan bahwa terdapat hubungan sikap kerja terhadap keluhan musculoskeletal disorder. ${ }^{2} \mathrm{Hal}$ tersebut karena pada saat melakukan aktivitas menunjukkan postur kerja yang salah dan posisi leher menunduk dalam waktu lama bisa menjadi salah satu yang mengakibatkan terjadinya nyeri leher yaitu myofascial triggers point syndrome. ${ }^{3}$

Myofascial pain syndrome merupakan salah satu gangguan muskuloskeletal yang ditandai dengan adanya trigger point di area yang sensitif di dalam taut band otot skeletal, jika diberikan tekanan pada area tersebut akan menimbulkan nyeri yang spesifik pada suatu titik yang ditekan (tenderness). Myofascial pain syndrome dapat menyebabkan nyeri lokal, tenderness, tightness, stiffness, nyeri rujukan dan kelemahan otot yang biasanya terjadi pada otot upper trapezius. ${ }^{4}$

Beberapa faktor yang mempengaruhi terjadinya myofascial pain syndrome diantaranya adalah masa kerja dan postur kerja. Berdasarkan latar belakang di atas bahwa dapat dilakukan penelitian tentang adanya hubungan postur kerja dan masa kerja dengan terjadinya myofascial pain syndrome pada penjahit.

\section{METODE}

Penelitian ini menggunakan rancangan penelitian analitik dengan pendekatan cross sectional. Sampel dianalisis berdasarkan masa kerja dan postur kerja. Masa kerja dianalisis melalui wawancara secara langsung kepada responden dan postur kerja dianalisis dengan menggunakan skor RULA.

Penelitian ini dilakukan di garmen yang berlokasi di Batubulan, Gianyar. Penelitian dilakukan pada bulan Mei hingga Juni 2019. Kriteria intrinsik sampel pada penelitian ini ialah: 1) jenis kelamin wanita, 2) berusia antara 30-45 tahun, 3) lama kerja per hari 8 jam, 4) bersedia mengisi informed consent. Kriteria ekstrinsik ialah: 1) memiliki riwayat cedera musculoskeletal dan neuro pada daerah leher sejak 6 bulan terakhir. 2) mengalami kelemahan otot pada daerah leher.

HASIL

Karakteristik sampel berdasarkan usia, masa kerja dan lama kerja adalah sebagai berikut:

Tabel 1. Karakteristik Sampel

\begin{tabular}{ll}
\hline Karakteristik & Nilai Rerata \pm Simpang Baku \\
\hline Usia (tahun) & $40,80 \pm 2,31$ \\
Masa Kerja (tahun) & $17,16 \pm 3,90$ \\
Lama Kerja (jam) & $8,00 \pm .00$ \\
\hline
\end{tabular}

Tabel 1 menunjukkan karakteristik sampel penelitian berdasarkan usia, masa kerja dan lama kerja pada penjahit di Batubulan. Karakteristik sampel berdasarkan usia diperoleh rata-rata 40,80 tahun dengan simpang baku 2,31. Karakteristik sampel berdasarkan Masa kerja diperoleh bahwa rata-rata masa kerja penjahit di Batubulan adalah 17,16 tahun dengan simpang baku 3,90. Karakteristik sampel berdasarkan lama kerja diperoleh bahwa rata-rata penjahit bekerja dalam waktu 8 jam sehari.

Tabel 2. Crosstabulation Hubungan Masa Kerja dengan MPS

\begin{tabular}{lcccc}
\hline Masa Kerja & \multicolumn{2}{c}{ MPS } & Jumlah & $\mathbf{p}$ \\
\cline { 2 - 3 } & Ya & Tidak & & \\
\hline 6-10 tahun & 19 & 21 & 40 & 0,000 \\
$>10$ tahun & 44 & 7 & 51 & \\
\hline Jumlah & 63 & 28 & 91 & \\
\hline
\end{tabular}

Tabel 2 menunjukkan hasil crosstabulation hubungan masa kerja dengan MPS pada penjahit garmen di Batubulan. Data menunjukkan bahwa pada sampel dengan masa kerja $>10$ tahun memiliki tingkat MPS lebih tinggi yaitu sebanyak 44 orang. 
Tabel 3. Crosstabulation Hubungan Postur Kerja dengan MPS

\begin{tabular}{lcccc}
\hline Postur Kerja & \multicolumn{2}{c}{ MPS } & Jumlah & p \\
\cline { 2 - 3 } & Ya & Tidak & & \\
\hline RULA 5-6 & 17 & 22 & 39 & 0,000 \\
RULA 7 & 46 & 6 & 52 & \\
\hline Jumlah & 63 & 28 & 91 & \\
\hline
\end{tabular}

Tabel 3 menunjukkan hasil crosstabulation hubungan postur kerja dengan MPS pada penjahit garmen di Batubulan. Data menunjukkan bahwa pada sampel dengan hasil skor RULA 7 memiliki tingkat MPS lebih tinggi yaitu sebanyak 46 orang.

Tabel 4. Hubungan Masa Kerja dengan MPS dengan Uji Spearman's Rho

\begin{tabular}{ccc}
\hline Variabel & \multicolumn{2}{c}{ MPS } \\
\cline { 2 - 3 } & $\mathbf{R}$ & $\mathbf{p}$ \\
\hline Masa Kerja & 0,417 & 0,000 \\
Postur Kerja & 0,481 & 0,000 \\
\hline
\end{tabular}

Berdasarkan data pada Tabel 4 diperoleh nilai $p=0,000(p<0,05)$ yang menunjukkan adanya hubungan yang signifikan antara masa kerja dengan MPS dan antara postur kerja dan MPS. Nilai $r=0,417$ antara masa kerja dengan MPS dan $r=0,481$ antara postur kerja dengan MPS. Nilai positif pada $r$ menunjukkan bahwa masa kerja dan postur kerja memiliki hubungan yang searah dengan MPS. Jika masa kerja semakin besar maka risiko MPS akan meningkat. Demikian pula dengan postur kerja, semakin besar nilai skor RULA maka risiko MPS akan meningkat.

\section{DISKUSI}

Sampel dengan jumlah 91 orang memiliki rentang usia 35 tahun sampai 45 tahun. Rata-rata usia sampel pada penelitian ini adalah 40,80 dengan simpang baku 2,31. Penelitian ini sesuai dengan hasil penelitian oleh Ching Yap yang menyatakan bahwa fungsi fisiologis tubuh mencapai puncaknya pada usia 30 tahun. ${ }^{5}$ Setelah usia tersebut, lama kelamaan fungsi fisiologis tubuh seperti kekuatan otot, dan stabilitas otot yang akan menurun sejalan dengan bertambahnya usia. Selain itu, setelah usia 40 tahun dapat terjadi degenerasi dengan adanya kerusakan pada jaringan, pergantian jaringan- jaringan yang diganti menjadi jaringan parut, serta adanya pengurangan cairan dalam tubuh. ${ }^{6}$ Pada usia dewasa hingga lanjut terdapat perubahan jelas yang terjadi. Salah satu efek dari adanya perubahan yaitu pada sistem otot, otot berada dalam posisi statik sehingga tidak terdapat penguluran jika kontraksi berlangsung lama maka akan menimbulkan tightness dan timbulnya myofascial. ${ }^{7}$

Masa kerja adalah total dari lamanya bekerja penjahit garmen di Batubulan saat menggunakan mesin jahit untuk menjahit dalam satu hari. Sesuai dengan penelitian ini di garmen batubulan memiliki lama kerja selama 8 jam dalam sehari. Pada penelitian ini, penjahit bekerja dalam waktu 8 jam dan istirahat selama 1 jam. Sampel pada penelitan ini berjumlah 91 orang penjahit garmen di batubulan. Terdapat 2 rentang masa kerja sampel yaitu antara 6 tahun hingga 10 tahun dan lebih dari 10 tahun. Sampel dengan masa kerja $6-10$ tahun sebanyak 40 orang (44\%) dan sampel dengan masa kerja lebih dari 10 tahun sebanyak 51 orang $(56 \%)$.

Masa kerja merupakan akumulasi aktivitas kerja seseorang yang dilakukan dalam jangka waktu yang panjang. Jika aktivitas tersebuat dilakukan secara terus menerus akan mengakibatkan gangguan pada tubuh. Tekanan fisik pada kurun waktu yang cukup lama mengakibatkan berkurangnya kinerja otot. Jika tekanan-tekanan terakumulasi setiap harinya pada suatu masa yang panjang dapat menyebabkan memburuknya kesehatan yang disebut juga kelelahan klinis atau kronis. Semakin lama dalam melakukan pekerjaan dapat menyebabkan terjadinya kejenuhan pada daya tahan otot dan tulan secara fisik maupun psikis. Bekerja dapat mempengaruhi kinerja dari orang tersebut. Pada penelitian ini, lama kerja penjahit pada penelitian ini adalah antara pukul 09.00 - 17.00 WITA dengan istirahat selama 1 jam. Menurut Zain, lama seseorang bekerja umumnya antara $6-8$ jam. ${ }^{8} \mathrm{Hal}$ ini juga sejalan dengan penelitian oleh Jalajuwita \& Paskarini yang mengatakan bahwa seseorang yang bekerja melebihi 4 jam kerja, maka produktivitas kerja dari pekerja akan menurun seiring dengan bertambahnya lama kerja. ${ }^{9}$ Oleh karena itu istirahat sangat penting dilakukan dilakukan oleh seseorang yang melakukan pekerjaan.

Berdasarkan penelitian yang telah dilakukan terdapat karakteristik sampel berdasarkan skor RULA. Dari 91 sampel yang ada diperoleh sampel dengan skor RULA sebesar 5-6 sebanyak 39 orang (42,9\%) dan sampel dengan skor RULA sebesar 7 sebanyak 52 orang $(57,1 \%)$. Postur kerja penjahit pada penelitian ini dinilai dengan menggunakan skor RULA. Menurut Santoso, postur kerja adalah proses kerja yang sesuai ditentukan oleh anatomi tubuh dan ukuran peralatan yang digunakan pada saat bekerja. ${ }^{10}$ Untuk bekerja dengan postur membungkuk ataupun menunduk dalam jangka waktu lama, pertimbangan ergonomi yang berkaitan dengan postur kerja dapat membantu mendapatkan postur kerja yang nyaman bagi seseorang yang melakukan pekerjaan, baik itu postur kerja berdiri, duduk ataupun postur kerja lainnya.

Penelitian ini didukung oleh penelitan yang dilakukan oleh Ayesa. Ayesa menyatakan bahwa terdapat hubungan postur kerja dengan terjadinya myofascial pain syndrome. Penelitian tersebut dilakukan pada 70 orang penjahit di Kecak Garmen. Penjahit dengan skor RULA lebih dari 5 ditemukan lebih banyak mengalami MPS. Pekerjaan yang berhubungan dengan mengoperasikan suatu alat tentu harus memperhatikan postur kerja agar tidak terjadi postur kerja yang tidak alamiah yang dapat menyebabkan adanya gangguan pada tubuh pekerja. ${ }^{11}$ Postur yang tepat yang harus diadopsi adalah leher tetap dalam posisi netral, tanpa kemiringan, fleksi dan ektensi ataupun rotasi, sehingga menjaga bidang visual di tingkat yang tepat. ${ }^{12}$

Karakteristik posisi kerja saat menjahit adalah duduk statis, forward head posture (kepala sedikit membungkuk), posisi siku dan lutut menekuk. Terdapat gerakan mengulang secara simultan pada tangan dan kaki saat menggunakan 
mesin jahit. Sikap tersebut dipertahankan dengan mata sebagai kontrol penglihatan dalam menjahit, tangan sebagai pengarah bahan yang dijahit dan kaki mengontrol kecepatan menjahit. ${ }^{13}$

Pada penelitian ini, hubungan postur kerja dengan terjadinya myofascial pain syndrome otot upper trapezius dapat diketahui dengan menggunakan spearman's rho yang menunjukkan nilai $p=0,000$. Hasil tersebut menyatakan $p$ $<0,05$ yang menunjukkan bahwa terdapat hubungan yang bermakna antara postur kerja dengan terjadinya myofascial pain syndrome otot upper trapezius.

Pada sampel dengan skor RULA 5-6 terdapat 22 orang tidak MPS dan 17 orang yang mengalami MPS. Pada sampel dengan skor RULA 7 terdapat 6 orang yang tidak mengalami MPS dan terdapat 46 orang yang mengalami MPS .Penilaian faktor postur kerja yang digunakan pada penelitian ini adalah RULA. Terdapat dialysis pada RULA seperti postur kerja, beban kerja, dan penggunaan otot. Dari peneltian yang telah dilakukan adalah bahwa tidak ada penjahit yang memiliki postur dengan skor RULA 1-2 dan 3-4 dan kebayakan memiliki postur kerja dengan skor RULA 5-6 dan 7 memiliki risiko tinggi yang diperlukan dilakukan perbaikan lebih lanjut.

Dari 91 sampel yang diteliti terdapat hal-hal yang ditemukan seperti adanya postur yang tidak baik. Pada postur punggung terlihat tidak ada sandaran sehingga otot punggung akan terus berkontraksi. Postur yang buruk juga ditemukan pada lengan bawah dan pergelangan tangan. Hal tersebut dikarenakan saat menjahit penjahit melakukan gerakan tangan yang fleksi dan pergelangan tangan tertekuk dikarenakan mesin jahit berada di atas meja. Hal tersebut dapat menyebabkan tangan cepat lelah. Pada postur leher juga ditemukan postur yang tidak baik karena leher terlalu menunduk saat melakukan pekerjan menjahit. Dikarenakan meja penjahit kurang baik dan terlalu rendah hal itu membuat otot -otot leher berkontraksi dan pada akhirnya menambah besarnya postur buruk pada penjahit saat bekerja. Pada postur kaki penjahit bahwa dapat terlihat kaki menekuk dan bersandar pada meja, postur seperti ini yang dapat membuat otot bekerja lebih keras serta menahan posisi seperti itu yang dapat menyebabkan kelelahan pada kaki.

Perbedaan yang dapat terlihat pada postur dengan skor 5-6 dengan skor 7 adalah postur dengan nilai skor 56 pada penilaian memiliki nilai lebih kecil. Pada postur dengan nilai 7 terlihat bahwa pada lengan atas cenderung fleksi 200 hingga 450 disertai dengan abduksi ataupun bahu yang dinaikan. Pada lengan juga terlihat lengan bawah cenderung fleksi kurang dari dari 600 atau lebih dari 1000 dan postur dengan skor 7 memiliki nilai yang tinggi pada leher dengan postur leher menunduk lebih dari 200 dan punggung yang membungkuk dari 20o hingga 600. Hal tersebut yang membuat total nilai RULA pada postur dengan skor 7 lebih tinggi dibandingkan postur dengan 5-6.

Postur merupakan suatu adaptasi anggota gerak tubuh. Postur tersebut dapat dilihat dari ukuran tubuh dan ukuran alat yang digunakan saat melakukan pekerjaan. Pada saat melakukan pekerjaan, postur saat kita bekerja harus sangat diperhatikan agar tetap dalam keadaan seimbang sehingga saat melakukan pekerjaan akan terasa lebih nyaman. Jika postur tubuh tidak dalam posisi normal menyebabkan myofascial pain syndrome otot upper trapezius. ${ }^{14}$

Sikap kerja yang tidak ergonomis atau tidak alamiah mengakibatkan posisi dari bagian tubuh menjauhi posisi yang alamiah seperti kepala dan leher yang menunduk, punggung yang terlalu membungkuk, pergerakan tangan keangkat keatas, dan lainnya. Sikap kerja yang tidak stabil tersebut, dikarenakan karakteristik dari tuntutan pekerjaan, alat kerja, maupun stasiun kerja yang tidak sesuai dengan kemampuan dan keterbatasan dari pekerja. ${ }^{15}$ Posisi menjahit yang buruk dapat menimbulkan pegal dan nyeri terutama leher, bahu, pinggang dan kaki. ${ }^{13}$ Menurut Pratama, duduk terlalu lama dengan posisi yang statis dan forward head position pada penjahit dapat meningkatkan resiko kerja berlebih pada daerah leher dan bahu. ${ }^{16}$ Resiko kerja yang berlebih tersebut meningkatkan spasme otot daerah leher dan bahu sehingga muncul nyeri pada daerah tersebut.

Berdasarkan penelitian yang telah dilakukan, penjahit di Batubulan mengoperasikan mesin jahit dan menjahit pakaian dalam waktu yang lama secara terus menerus. Pekerjaan tersebut makin bertambah jika adanya permintaan dari konsumen dalam jumlah yang lebih banyak dari biasanya. Selanjutnya, hal inilah yang menyebabkan postur kerja yang tidak baik berlangsung secara berulang- ulang. Jika pekerjaan dengan postur yang tidak baik maka akan menimbulkan keteganggan pada otot yang dapat menurunkan sirkulasi pada jaringan dan memicu munculnya taut band dan dapat menimbulkan myofascial pain syndrome. ${ }^{17}$

Otot Upper Trapezius merupakan otot tonik atau otot postural yang bekerja dalam gerakan leher dan bahu. Kerja otot ini akan bertambah dengan adanya postur yang jelek (foreward head posture), ataupun akibat dari ergonomi kerja yang buruk disertai dengan trauma mikro dan makro serta degenerasi otot dan fasia. Kontraksi otot upper trapezius yang berlangsung secara kontinu akan mengakibatkan terjadinya spasme, collagen contracture, adhesion, abnormal crosslink actin myosin, serta penurunan sirkulasi darah pada daerah tersebut yang menjadi pemicu munculnya trigger points pada taut band yang akan menimbulkan nyeri myofascial. ${ }^{18}$

Pada penelitian ini, ditemukan sampel dengan masa kerja 6-10 tahun sebanyak 21 orang tidak MPS dan 19 orang yang mengalami MPS. Pada sampel dengan masa kerja lebih dari 10 tahun terdapat 7 orang yang tidak mengalami MPS dan terdapat 44 orang yang mengalami MPS. Dari hasil penelitian yang dilakukan, ditemukan bahwa terdapat hubungan yang searah antara masa kerja dengan MPS. Semakin lama masa kerja seorang penjahit, maka akan semakin tinggi risiko terjadinya MPS.

Masa kerja merupakan akumulasi aktivitas kerja seseorang yang dilakukan dalam jangka waktu yang panjang. Apabila aktivitas tersebut dilakukan terus-menerus akan mengakibatkan gangguan pada tubuh. Tekanan fisik pada suatu kurun waktu tertentu mengakibatkan berkurangnya kinerja otot, dengan gejala makin rendahnya gerakan. Tekanan-tekanan akan terakumulasi setiap harinya pada suatu masa yang panjang, sehingga mengakibatkan memburuknya kesehatan yang disebut juga kelelahan klinis atau kronis. Semakin lama kerja seseorang dapat menyebabkan terjadinya kejenuhan pada daya tahan otot dan tulang secara fisik maupun psikis.

Masa kerja adalah salah satu faktor yang dapat menjadi faktor pemicu munculnya MPS yang dapat disebabkan oleh pekerjaan dikarenakan peningkatan masa kerja yang dilakukan oleh pekerja secara berulang. Sehingga dapat menimbulkan kelelahan pada jaringan. Hal ini jaringan otot yang dapat menyebabkan overuse, sehingga dapat menimbulkan spasme pada otot. Masa kerja yang merupakan akumulasi aktivitas kerja seseorang yang dilakukan 
dalam jangka waktu yang panjang. Semakin lama kerja seseorang dapat menyebabkan terjadinya kejenuhan pada daya tahan otot dan tulang secara fisik maupun psikis. Menurut Hendra dan Suwandi Rahardjo dalam jurnal nasional IX Ergonomic, bahwa pekerja yang mempunyai masa kerja lebih dari 4 tahun mempunyai risiko gangguan muskuloskeletal 2,775 kali lebih besar dibandingkan dengan pekerja dengan masa kerja $\leq 4$ tahun. Dan menurut Boshuzen, masa kerja yang lebih dari 5 tahun memiliki risiko lebih tinggi untuk merasakan nyeri. ${ }^{19}$ Hasil penelitian yang dilakukan pada penjahit garmen di Batubulan menunjukkan bahwa sebagian sampel merupakan pekerja dengan masa kerja lebih dari 10 tahun. Penelitian ini didukung oleh Rahman yang menyatakan bahwa semakin lama masa kerja seseorang maka akan semakin lama pula orang tersebut terkena atau terpapar oleh faktor- faktor risiko seperti faktor lingkungan kerja secara fisik. ${ }^{14}$ Masa kerja merupakan faktor risiko yang sangat mempengaruhi seorang pekerja untuk meningkatkan risiko terjadinya myofascial pain syndrome terutama untuk jenis pekerjaan yang menggunakan kekuatan kerja yang tinggi dan dalam waktu yang lama seperti seorang penjahit. ${ }^{20}$

Penelitian ini tidaklah sempurna, terdapat beberapa kekurangan yang dapat menjadi faktor bias pada penelitian ini. Faktor internal yang mempengaruhi myofascial pain syndrome diantaranya ialah jenis kelamin, usia, dan IMT. Pada penelitian ini IMT tidak termasuk variabel kontrol, oleh karena itu IMT dapat menyebabkan bias pada hasil penelitian ini. Selain faktor internal, myofascial pain syndrome juga dipengaruhi oleh faktor eksternal yaitu alat kerja yang digunakan penjahit. Alat kerja dapat mempengaruhi postur kerja penjahit. Pada penelitian ini alat kerja tidak termasuk variabel kontrol, oleh karena itu dapat menjadi bias pada penelitian ini.

Berdasarkan penelitian yang telah dilakukan maka saran yang dapat diberikan yaitu penjahit diharapkan dapat melakukan stretching pada daerah ekstremitas atas untuk mencegah kekauan otot dan kelelahan. Perusahan sebaiknya memberikan fasilitas yang memadai untuk para pekerja seperti meja menjahit dan kursi dengan sandaran punggung agar dapat mengurangi cedera kerja.

Bagi peneliti yang ingin melanjutkan penelitian ini, diharapkan dapat meneliti hubungan antara postur dan masa kerja penjahit dengan terjadinya MPS pada otot lain oleh karena penelitian ini hanya terbatas pada otot upper trapezius saja. Menjahit juga melibatkan otot-otot di tangan dan punggung yang dapat berisiko mengalami MPS

\section{SIMPULAN}

Berdasarkan penelitian yang telah dilakukan, ditemukan bahwa terdapat hubungan postur kerja dan masa kerja dengan terjadinya myofascial pain syndrome otot upper trapezius pada penjahit di batubulan. Dan dapat juga yang dilihat bahwa ada faktor yang lain yang dapat mempengaruhi yaitu usia.

\section{DAFTAR PUSTAKA}

1. Aryanto, PW. 2008. Gambaran Risiko Ergonomi dan Keluhan Gangguan Muskuloskeletal pada Penjahit Sektor Usaha Informal [Skripsi]. Jakarta: Universitas Indonesia.

2. Sihombing, PA. 2015. Hubungan Sikap Kerja Dengan Musculoskeletal Disorders Pada Penjahit Di Pusat Industri Kecil Menteng Medan 2015. Journal of USU, 2(1).

3. Sang B. 2004. Pengaruh Posisi Kerja Terhadap Timbulnya Nyeri Punggung Bawah Pada Pengrajin Rotan Di Desa Trangsan Kabupaten Sukoharjo. Infoke 8 (1).

4. Dhita, 2015. Kombinasi Strain Counterstrain Dan Infrared Sama Baik Dengan Kombinasi Contract Relax Stretching Dan Infrared Terhadap Penurunan Nyeri Myofascial Pain Syndrome Otot Upper Trapezius Pada Mahasiswa Fisioterapi Fakultas Kedokteran Universitas Udayana. Majalah IImiah Fisioterapi Indonesia, 3(1).

5. Ching Yap, Eng. 2007. Myofascial Pain An Overview. Ann Acad Med Singapre, 36(1).

6. Sari, EN., Handayani, Lina., Saufi, Azidanti. 2017. Hubungan Antara Umur dan Masa Kerja dengan Keluhan Musculoskeletal Disorders (MSDs) pada Pekerja Laundry. Jurnal Kedokteran dan Kesehatan, 13(2).

7. Makmuriyah dan Sugijanto. 2013. Ionthophoresis Diclofenac Lebih Efektif Dibandingkan Ultrasound Terhadap Pengurangan Nyeri Pada Myofascial Syndrome Musculus Upper Trapezius. Jurnal Fisioterapi, 13(1).

8. Zain, Asrori. 2017. Sikap Kerja dan Kejadian Myofascial Pain Syndrome Pada Leher dan Bahu Pemetik Kopi di Desa Pasrujambe Kabupaten Lumajang [Skripsi]. Bagian Kesehatan Lingkungan dan Kesehatan keselamatan Kerja : Universitas Jember.

9. Jalajuwita, R.N dan Paskarini, Indriati. 2015. Hubungan Posisi Kerja dengan Keluhan Musculoskeletal pada Unit Pengelasan PT. X Bekasi. The Indonesian Journal of Occupational Safety and Health 4(1): 33-42.

10. Santoso. 2004. Ergonomi Manusia, Peralatan dan Lingkungan. Cetakan I. Jakarta: Prestasi Pustaka.

11. Setyawan, F.E.B. 2011. Penerapan Ergonomi Dalam Konsep Kesehatan, 7(14).

12. Onety, G.C., Leonel, D.V., Saquy, P.C., Silva, G.P., Ferreira, B., Varise, T.G., Sousa, L.G., Verri, E.D., Siessere, S., Semprini, M., Nepomuceno, V.R., Regalo, S.C. 2014. Analysis of Endodontist Posture Utilizing Cinemetry Surface Electromyography and Ergonomic Checklists. Brazilian Dental Journal, 25(6): 508-518.

13. Cael.Christy. 2010. Function Anatomy: Musculoskeletal Anatomy, Kinesiology, and Palpation For Manual Therapists. Lippincott Williams \& Wilkins, Wolters Kluwer Health.

14. Rahman, Abdul. 2017. Analisis Postur Kerja dan Faktor yang Berhubungan dengan Keluhan Musculoskeletal Disorders (MSDs) pada Pekerja Beton Sektor Informal di Kelurahan Samata Kecamatan Somba Opu Kabupaten Gowa Tahun 2017 [Skripsi]. Makassar : Fakultas Kedokteran dan Ilmu Kesehatan Universitas Islam Negeri Alauddin.

15. Evadarianto, Nurdian dan Dwiyanti, Endang. 2017. Postur Kerja dengan Keluhan Musculoskeletal Disorders pada Pekerja Manual Handling Bagian Rolling Mill. The Indonesian Journal of Occupational Safety and Health, 6(1): 97106. 
16. Pratama, G.R. 2013. Pengaruh Latihan Contract Relax Stretching Terhadap Penurunan Nyeri Myofascial Trigger Point Syndrome Otot Upper Trapezius Pada Pembatik Tulis Halus Laweyan [Skripsi]. Surakarta: Program Studi Fisioterapi Fakultas Kedokteran Universitas Muhammadyah.

17. Bayzid, Bahauddin. 2016. Prevalence of Musculoskeletal Disorders Among The Garment Workers in Dhaka City. Bangladesh Health Professions Institute (BHPI).

18. Dommerholt, J. Bron, C. and Fransen, J. 2006. Myofascial Trigger Point : An Evidence Informed Review. The Journal of Manual and Manipulatif Therapy. USA, 14 (4): 203-221.

19. Bron, C. and Dommerholt, J. 2012. Etiology of Myofascial Trigger Points. Curr Pain Headache Rep., 16:439-444.

20. Icsal, M.M.A., Sabilu, Yusuf., Pratiwi, A.D. 2016. Faktor Yang Berhubungan Dengan Keluhan Musculoskeletal Disorders (MSDs) Pada Penjahit Wilayah Pasar Panjang Kota Kendari Tahun 2016. Jurnal IImiah Mahasiswa Kesehatan Masyarakat,1(2). 